\title{
Effects of ultrasonic waves on carbon dioxide solubility in brine at different pressures and temperatures
}

\author{
Hossein Hamidi ${ }^{1}$ Erfan Mohammadian ${ }^{2}$ - Amin Sharifi Haddad ${ }^{1}$. \\ Roozbeh Rafati ${ }^{1}$ - Amin Azdarpour ${ }^{3}$ - Panteha Ghahri ${ }^{1}$ - Adi Putra Pradana ${ }^{1}$ \\ Bastian Andoni $^{1} \cdot$ Chingis Akhmetov ${ }^{1}$
}

Received: 26 October 2016/Published online: 13 July 2017

(C) The Author(s) 2017. This article is an open access publication

\begin{abstract}
The adverse impacts of $\mathrm{CO}_{2}$ emission on the global warming highlight the importance of carbon capture and storage technology and geological storage of $\mathrm{CO}_{2}$ under solubility trapping mechanisms. Enhancing the solubility of $\mathrm{CO}_{2}$ in formation water has always been the focus of research in the area of $\mathrm{CO}_{2}$ sequestration. Ultrasound techniques are one of the environmentally friendly methods that use high-intensity acoustic waves to improve gas solubility in liquids. Ultrasonic waves can alter the properties of different phases that lead to chemical reactions and provide a means to increase the solubility of $\mathrm{CO}_{2}$ in connate water. In this study, we investigated the effects of ultrasound on the solubility of $\mathrm{CO}_{2}$ in connate water under different conditions of pressure, temperature, and salinity. The results showed that the solubility of $\mathrm{CO}_{2}$ was improved with increasing pressure under ultrasonic effects. However, the solubility of $\mathrm{CO}_{2}$ was inversely proportional to the increase in brine salinity and temperature. Therefore, it was concluded that the solubility of $\mathrm{CO}_{2}$ might be enhanced in the presence of ultrasound.
\end{abstract}

Keywords Carbon dioxide $\cdot \mathrm{CO}_{2}$ sequestration . Ultrasound · High-frequency waves · Solubility

Hossein Hamidi

hossein.hamidi@abdn.ac.uk

1 School of Engineering, King's College, University of Aberdeen, Aberdeen AB24 3UE, UK

2 Faculty of Chemical Engineering, University Technology MARA, 40450 UiTM Shah Alam, Malaysia

3 Department of Petroleum Engineering, Marvdasht Branch, Islamic Azad University, Marvdasht, Iran

Edited by Xiu-Qin Zhu

\section{Introduction}

Excessive emission of carbon dioxide $\left(\mathrm{CO}_{2}\right)$ into the atmosphere is one of the environmental challenges which causes critical effects such as sea level rise, melting of arctic ice, and increase in the earth's temperature, which is called the phenomenon of global warming. Concerns about global warming and challenges of $\mathrm{CO}_{2}$ emission reduction highlight the need to develop effective and economical means for $\mathrm{CO}_{2}$ sequestration (Brooks 1950; Metz et al. 2005; Bachu 2000; Bryant 2007; Gibson-Poole et al. 2007; Sengul 2006). In subsurface $\mathrm{CO}_{2}$ sequestration, a large amount of $\mathrm{CO}_{2}$ is injected into deep aquifers. Thus, $\mathrm{CO}_{2}$ can be stored permanently to reduce its net emissions into the atmosphere (Bachu 2000; Reichle et al. 1999).

Nguyen (2003) suggested four methods for geological storage of $\mathrm{CO}_{2}$ : (1) utilization of $\mathrm{CO}_{2}$ for enhanced oil recovery (EOR) processes, (2) use of $\mathrm{CO}_{2}$ to improve recovery from coal-bed methane, (3) injection of $\mathrm{CO}_{2}$ into depleted oil and gas reservoirs, and (4) injection of $\mathrm{CO}_{2}$ into deep saline aquifers. Among these methods, saline aquifers are most anticipated due to their considerable storage capacity and extensive distribution around the world (Metz et al. 2005; Bachu 2000; Schrag 2007).

Geological storage of $\mathrm{CO}_{2}$ in saline aquifers would preferentially occur under supercritical conditions. It depends on the contribution of several $\mathrm{CO}_{2}$-trapping mechanisms such as (1) physical trapping of a $\mathrm{CO}_{2}$ plume, (2) solubility trapping, which is the dissolution of $\mathrm{CO}_{2}$ compounds in the formation fluids (hydrocarbon and brine), (3) hydrodynamic trapping, which is basically quite similar to non-wet trapping of oil within individual pores that are not connected, and (4) mineral trapping (or mineralization), which is defined as formation of carbonates 
due to the reactions of $\mathrm{CO}_{2}$, brine and reservoir fluids (Paul et al. 2010).

Among the aforementioned mechanisms by which $\mathrm{CO}_{2}$ is rendered immobile, solubility and mineralization are the ones that could be manipulated. Therefore, one could expect the improvement in the efficiency of $\mathrm{CO}_{2}$ sequestration though an increase in the amount of $\mathrm{CO}_{2}$ sequestrated by these two mechanisms. The mineralization of $\mathrm{CO}_{2}$ is a very slow process, and despite the efforts for its expedition, it requires at least few hundred years to be accomplished (Azdarpour et al. 2015). The solubility mechanism, on the other hand, is much more rapid than the mineralization process. Therefore, the aim of this research is to increase the solubility of $\mathrm{CO}_{2}$ in $\mathrm{NaCl}$ solution using an unconventional method of ultrasound waves.

At low pressures, there are a large number of data sets on the solubility of $\mathrm{CO}_{2}$ in brine (Carroll et al. 1991; Zheng et al. 1997). However, due to the fact that in $\mathrm{CO}_{2}$ sequestration process, $\mathrm{CO}_{2}$ is injected as a supercritical fluid, high-pressure investigation and analysis are needed. Wiebe and Gaddy (1939) have conducted one of the first studies on the solubility of $\mathrm{CO}_{2}$ in water under high-pressure conditions. Thereafter, other measurement methods were used to investigate the solubility of $\mathrm{CO}_{2}$ in water at different pressure and temperature conditions (King et al. 1992; Bamberger et al. 2000). To date, the solubility of $\mathrm{CO}_{2}$ has been studied by many researchers over a wide range of salinity, temperature and pressure conditions (Rumpf et al. 1994; Koschel et al. 2006; Li et al. 2004; ElMaghraby et al. 2012; Mao et al. 2013; Shedid and Adel 2013; among others).

Two widely used techniques for measuring the solubility of $\mathrm{CO}_{2}$ are the volumetric technique and the combination technique (Peper and Dohrn 2012; Yan et al. 2011; Tong et al. 2013). Both of these techniques are slow; consequently, studies have been performed to improve and accelerate solubility measurements through these methods (El-Maghraby et al. 2012). Portier and Rochelle (2005) for the first time introduced the potentiometric titration technique to measure the solubility of $\mathrm{CO}_{2}$. However, the experimental results achieved by this technique were limited to a particular formation brine, with a limited range of salinity, pressure, and temperature conditions. Most recently, Mohammadian et al. (2015) reported the solubility of $\mathrm{CO}_{2}$ in brine at different salinity, pressure, and temperature conditions, using the potentiometric titration method. They found that increasing pressure enhances the solubility of $\mathrm{CO}_{2}$ in distilled water and brine, and as the temperature increases, regardless of brine salinity, $\mathrm{CO}_{2}$ solubility significantly reduces and salinity itself showed an adverse effect on the solubility of $\mathrm{CO}_{2}$. Finally, the method was proved to be reproducible, fast, and accurate in comparison with the previous conventional methods.
On the other hand, application of ultrasound waves is an environmental friendly technology, which is known to improve chemical reactions in multiphase systems (Mason 1990). The use of such technique has successfully been implemented in a number of fields of science and engineering, such as food, chemical, oil and gas industries. In oil and gas industry, hydrocarbon recovery from oil reservoirs using vibration methods dates back to 1950s when an increase in oil production was observed as a result of cultural noise and earthquakes. During penetration of nonlinear low-frequency elastic waves through porous media, wave shapes might be distorted due to energy loss and attenuation, which makes them harmonic with higher frequencies. Then, one might expect the propagation of ultrasonic waves in the subsurface environment while sending low-frequency elastic waves from the surface (seismic) or due to earthquake nonlinear plane waves (Naderi and Babadagli 2010). A large number of studies have been conducted on the effects of ultrasound on enhanced oil recovery processes, emulsification of oil and brine, oil viscosity, oil mobilization in porous media, phase behaviour of a surfactant-brine-oil system, liquid-liquid interaction, and chemical treatment of horizontal wells (Hamidi et al. 2012, 2013, 2015a, b; Hamida and Babadagli 2006, 2007; Naderi and Babadagli 2010; Abramov et al. 2013, 2015, 2016). All of these studies have shown promising results after applying ultrasonic waves for testing processes.

Samenov et al. (2010) investigated the kinetics of dissolution of a single bubble of $\mathrm{CO}_{2}$ in a glass column of water under ultrasound at low-pressure and temperature conditions. They studied the dissolution of $\mathrm{CO}_{2}$ bubbles in water during free rise to the surface, in the presence and absence of ultrasound. Based on their studies, it was found that the dissolution of $\mathrm{CO}_{2}$ bubbles was enhanced as a result of increase in the rate of mass transfer of $\mathrm{CO}_{2}$ into water phase through imposed acoustic vibrations. This might be due to the fact that ultrasonic waves excited the molecular structure of water, where $\mathrm{CO}_{2}$ molecules can easily get trapped between them.

Since there is very limited reported data on the effects of ultrasound on the solubility of $\mathrm{CO}_{2}$, in this study, we investigated the effects of ultrasonic waves on the solubility of $\mathrm{CO}_{2}$ at different brine salinity, temperature, and pressure conditions. We used the potentiometric titration technique to conduct our experiments. One of the main advantages of titration method for measuring the solubility of $\mathrm{CO}_{2}$ is the conservation of samples, which inhibits $\mathrm{CO}_{2}$ loss as a result of degassing during depressurization, while it is accurate and easy to use. Moreover, unlike previous studies, there is no need to estimate parameters, such as fugacity and density. 


\section{Materials and methods}

\subsection{Materials}

Deionized and distilled water (Milli-Q) with $18.2 \Omega$ resistivity was used to prepare brine with different salinities. In our experiments, we used $\mathrm{NaCl}$ with the purity of 0.995 (mass fraction) provided by Systerm, and $\mathrm{CO}_{2}$ with a purity of $99.99 \%$ was provided by the SIG.

\subsection{Methods}

In this study, a series of experiments were performed to investigate the effects of ultrasound on the solubility of $\mathrm{CO}_{2}$ in brine at high-pressure and temperature conditions. For this purpose, a customized experimental set-up was developed as shown in Fig. 1. It consists of a Genesis TM XG-500-6 ultrasonic wave generator, $\mathrm{CO}_{2}$ cylinder, ISCO pump made by Teledyne (model $100 \mathrm{DX}$ ), 100-mL autoclave reactor equipped with ultrasound transducers, and a magnetic stirrer. The reactor was enclosed in an electric heater. The ultrasonic generator emits ultrasonic waves at a frequency of $40 \mathrm{kHz}$ with a power of $500 \mathrm{~W}$. A thin $(d=3.2 \mathrm{~mm})$ dipping tube was attached to a floatingpiston-type sampler fabricated locally, which was operated by a KD Scientific syringe pump. The dip tube was used for the sampling from the solution of $\mathrm{CO}_{2}$-saturated brine.
To regulate the pressure in our experiments, the ISCO pump was used. The autoclave reactor was placed in an electric oven with adjustable temperature with a precision of $0.1{ }^{\circ} \mathrm{C}$. Even with a thick reactor base of $0.85 \mathrm{~cm}$, sufficient coupling between the magnetic stirrer and the bead was established that in turn leads to a thoroughly homogeneous solution. The reactor was heated up to the desired temperatures after the brine was introduced to it. $\mathrm{CO}_{2}$ was injected into the reactor and pressurized to the desired level where $2 / 3$ of the reactor $(\sim 70 \mathrm{~mL})$ was filled with an aqueous phase (brine or distilled water). In a closed system, the solution was stirred for $3 \mathrm{~h}$ until equilibrium was achieved. Required time to reach the equilibrium has been reported to be between $10 \mathrm{~min}$ and $24 \mathrm{~h}$ in previous studies (El-Maghraby et al. 2012; Peper and Dohrn 2012; Portier and Rochelle. 2005; Yan et al. 2011).

A sample of $\mathrm{CO}_{2}$-laden brine was taken from the reactor using the dipping tube, which was equipped with a floating piston. Through the sampling chamber, it reacts with the base solution $(0.5 \mathrm{M} \mathrm{NaOH})$ that filled half of the chamber $(\sim 3 \mathrm{~mL})$. This process helps in preserving of any sort of dissolved carbon types in the solution.

The other half of the sampling chamber was filled with distilled water, which was slowly withdrawn to allow $\mathrm{CO}_{2}$ saturated brine to react with the basic solution of $\mathrm{NaOH}$. It should be noted that a time period of $10 \mathrm{~min}$ was set for the

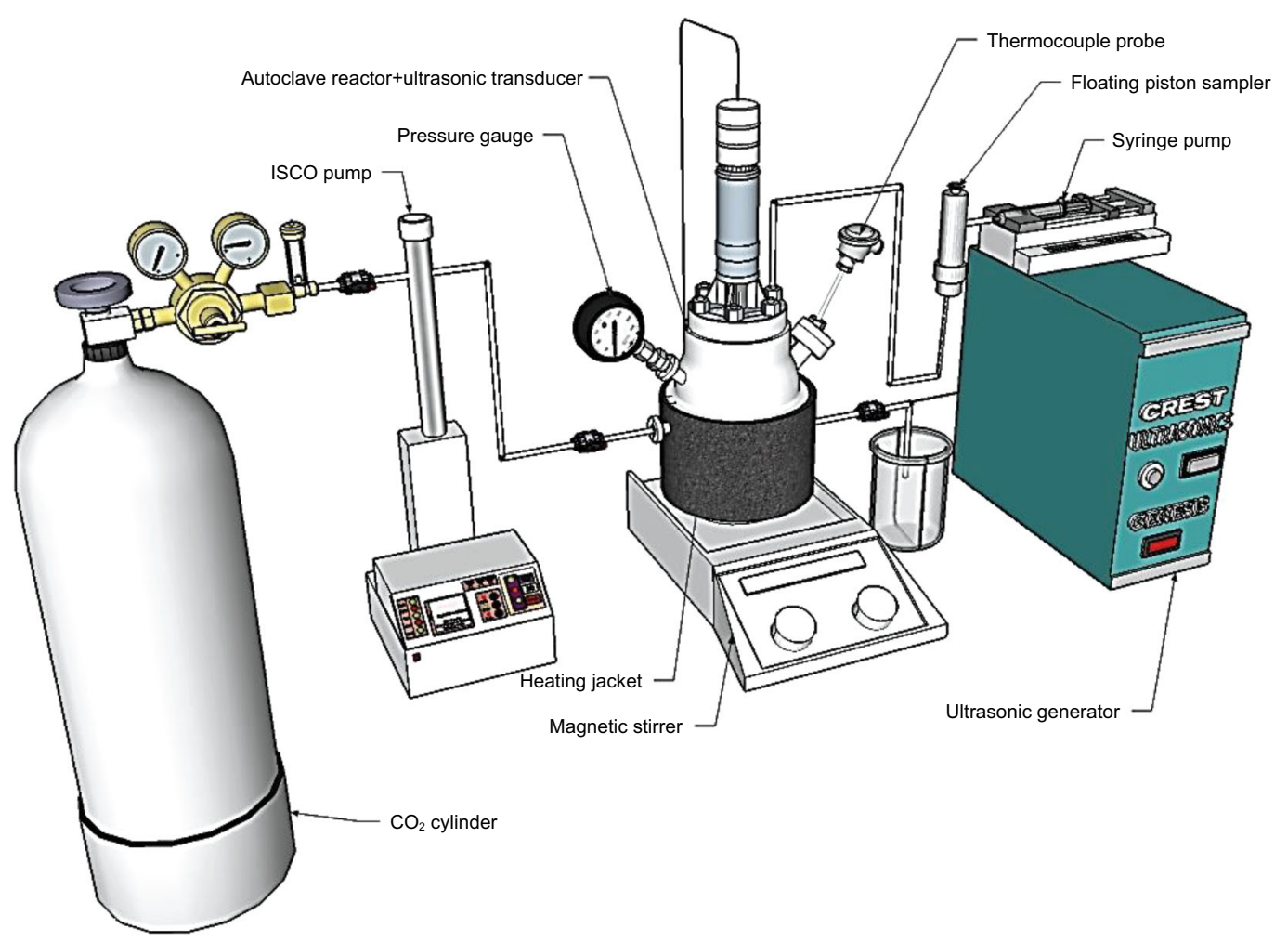

Fig. 1 Experimental set-up 
reaction of solution with $\mathrm{NaOH}$ prior to its removal from the chamber.

During the withdrawal, no gas bubbles were generated as all types of carbon species (including $\mathrm{H}_{2} \mathrm{CO}_{3}$ ) were dissolved in the $\mathrm{NaOH}$ and converted to basic solution $(\mathrm{NaOH})$ (Portier and Rochelle 2005; Duan and Sun 2003).

The potentiometric titration method was then used to analyse the samples of the aqueous $\mathrm{NaOH}$ solution. The equivalence point of titration can be identified via various methods, such as potentiometric (used in this research), indicators, and conductivity methods. Consumed volume of the reactant was measured and used to determine the concentration of analyte through the following correlation:

$C_{\mathrm{a}}=\frac{C_{\mathrm{t}} \times V_{\mathrm{t}} \times N}{M_{\mathrm{a}}}$

where $C_{\mathrm{a}}$ is the concentration of the analyte, which is equal to $\mathrm{CO}_{2}$ solubility in brine, in molal units $\left(\mathrm{mol} \mathrm{kg}^{-1}\right) ; C_{\mathrm{t}}$ is the concentration of titrant $(\mathrm{HCl})$, typically in $\mathrm{mol} \mathrm{L}^{-1} ; V_{\mathrm{t}}$ is the consumed volume of titrant, in $\mathrm{mL} ; N$ is the mole ratio of the analyte and reactant from the balanced chemical equation; and $M_{\mathrm{a}}$ is the mass of sample that is titrated in grams. The advantage of using mass of the solution $\left(M_{\mathrm{a}}\right)$, instead of its volume $V_{\mathrm{a}}$, which has been commonly used in previous studies, is that the mass of solution is not a function of pressure or temperature. Therefore, the level of uncertainty in solubility measurements is lowered. For acidity analysis, $0.5 \mathrm{M} \mathrm{HCl}$ used with a $5 \mathrm{~mL}$ sample as a titrant. The $\mathrm{pH}$ of the sample was closely monitored with added volume of titrant, and the titration continued until a $\mathrm{pH}$ less than 2 was achieved. The equivalence points were obtained using the derivative curves of titrant volume versus $\mathrm{pH}$. All these experiments were also conducted for the cases in which ultrasonic waves were applied.

\section{Results and discussion}

In the first series of experiments, effects of ultrasound (US) on the solubility of $\mathrm{CO}_{2}$ in distilled water at different pressure (1-210 atm) and temperature $\left(60,80\right.$, and $\left.100{ }^{\circ} \mathrm{C}\right)$ conditions were investigated, and the results were compared with the cases where no source of ultrasound (NUS) was used (Fig. 2). In the second series of experiments, effects of ultrasound on the solubility of $\mathrm{CO}_{2}$ in brine solutions with different salinities (1000 and 10,000 ppm) were investigated. These tests are designed to ensure that results are comparable to the conditions of saline aquifers (Figs. 3, 4). To analyse the experimental results, data analysis software (SPSS 18) was used, where it can eliminate any abnormally low or high data points. A couple of experiments were repeated three times (namely the solubility of carbon dioxide at 60,80 , and $100{ }^{\circ} \mathrm{C}$ in distilled water, for both 1000 and $10,000 \mathrm{ppm}$ brine salinity in the absence of ultrasound), and tolerance of the observed data was in the order of $\pm 5 \%$.

Figure 2 shows the solubility of $\mathrm{CO}_{2}$ in distilled water at 60,80 , and $100{ }^{\circ} \mathrm{C}$. The error bars represent $5 \%$ deviation from the base case $\left(60{ }^{\circ} \mathrm{C}\right)$. It is apparent from Fig. 2 that an increase in pressure improved the solubility of $\mathrm{CO}_{2}$ in brine solution at all tested temperatures in this study. In addition, the solubility of $\mathrm{CO}_{2}$ at high-pressure conditions became independent from pressure at all temperatures. Therefore, the solubility curves showed a plateau behaviour at pressures higher than $150 \mathrm{~atm}$. On the other side, temperature showed an inverse relationship with the solubility of $\mathrm{CO}_{2}$. It was observed that an increase in temperature caused a reduction in the solubility of $\mathrm{CO}_{2}$ in brine. For instance, as shown in Fig. 2, the solubility at 80 atm and $60{ }^{\circ} \mathrm{C}$ was $0.929 \mathrm{~mol} \mathrm{~kg}^{-1}$, whereas under the same pressure and at 80 and $100{ }^{\circ} \mathrm{C}$, the solubility was 0.771 and $0.679 \mathrm{~mol} \mathrm{~kg}^{-1}$, respectively. The solubility of $\mathrm{CO}_{2}$ in brine solutions $(\mathrm{NaCl})$ with concentration of 1000 and 10,000 ppm is presented in Figs. 3 and 4. The error bars in these three figures illustrate $5 \%$ deviation from the base case $\left(60^{\circ} \mathrm{C}\right)$. Brine solutions showed similar responses to temperature and pressure changes as distilled water. For example, in 10,000 ppm brine (Fig. 4) as the temperature was raised from the initial value of $60-100{ }^{\circ} \mathrm{C}$, a solubility reduction, depending on the pressure of between $5 \%$ and $24 \%$, was observed. It can be concluded from the results presented in Figs. 2, 3 and 4 that regardless of the salinity and temperature, an increase in pressure resulted in a higher $\mathrm{CO}_{2}$ dissolution in brine. This is due to the fact that at higher pressure, $\mathrm{CO}_{2}$ molecules are closer to each other and their vibration energies are decreased; therefore, they can be more easily dissolved in the aqueous phase and make bonds with water molecules. Overall, it is apparent that the solubility of $\mathrm{CO}_{2}$ is more sensitive to the changes of pressure and temperature where $\mathrm{CO}_{2}$ is in subcritical (liquid or gas) conditions, rather than the supercritical state.

Thermodynamically, a rise in temperature leads to an increase in the kinetic energy of the molecules, more rapid motions of the molecules, and therefore easier breakage of intermolecular bonds. This process enables the molecules to escape from liquid phase into the gas phase (Zumdahl 2002). Tests at different salinities of brine showed that the solubility of $\mathrm{CO}_{2}$ decreased with an increase in the salinity of brine at different pressure and temperature conditions. This can be explained by the fact that $\mathrm{Na}^{+}$and $\mathrm{Cl}^{-}$ions from the salt attract water molecules to "solvate"; thus, the number of free water molecules available to be attracted by $\mathrm{CO}_{2}$ molecules is decreased. Therefore, salinity decreases the weak affinity of $\mathrm{CO}_{2}$ molecules to water and drives the dissolved $\mathrm{CO}_{2}$ away from the polar water molecules. It can be concluded 

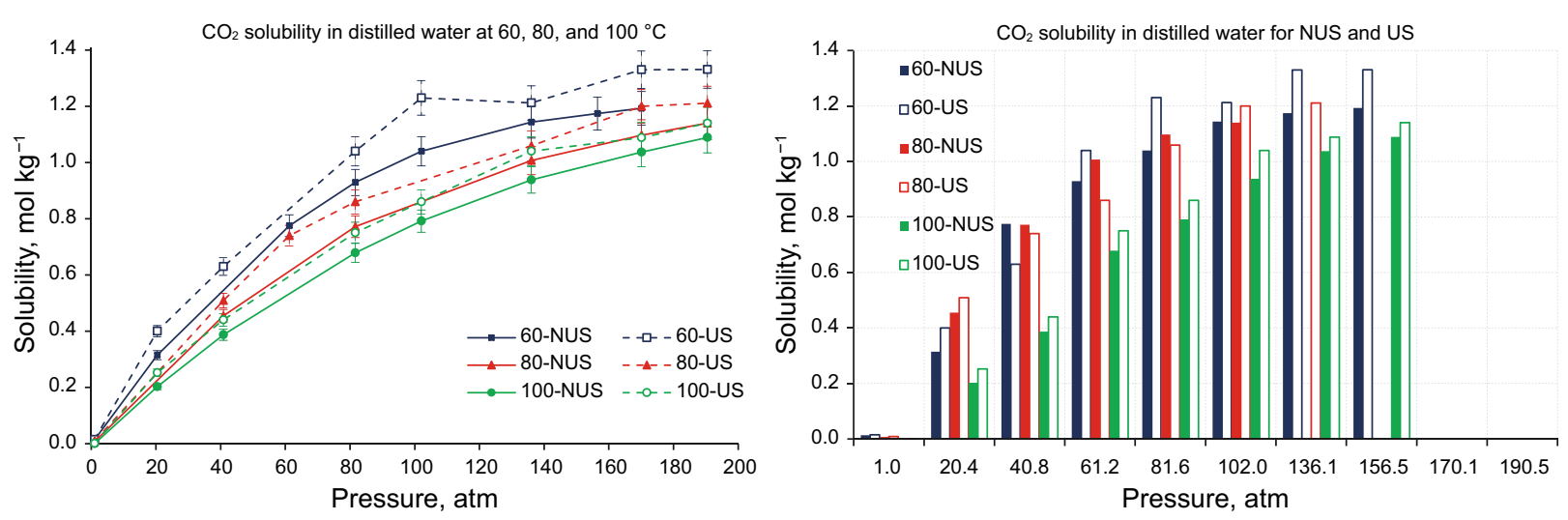

Fig. 2 The effect of ultrasound on solubility of $\mathrm{CO}_{2}$ in distilled water at 60,80 , and $100{ }^{\circ} \mathrm{C}$ (US with ultrasound, NUS no ultrasound)
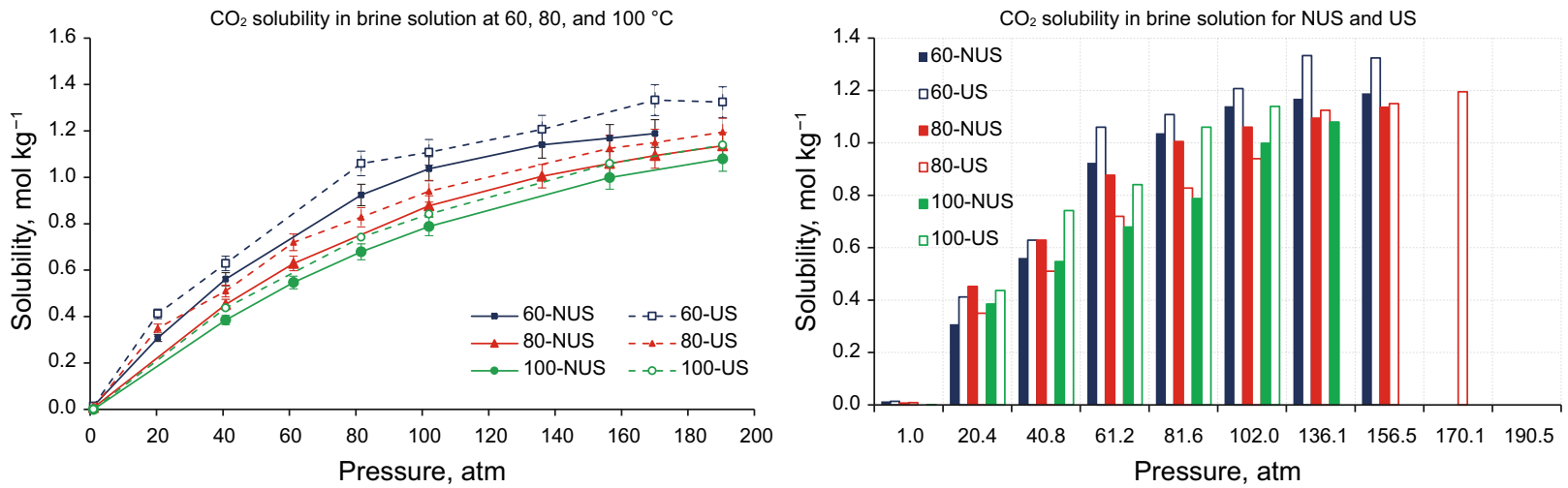

Fig. 3 The effect of ultrasound on solubility of $\mathrm{CO}_{2}$ in brine solution $(1000 \mathrm{ppm})$ at 60,80 , and $100{ }^{\circ} \mathrm{C}$ (US with ultrasound, $N U S$ no ultrasound)
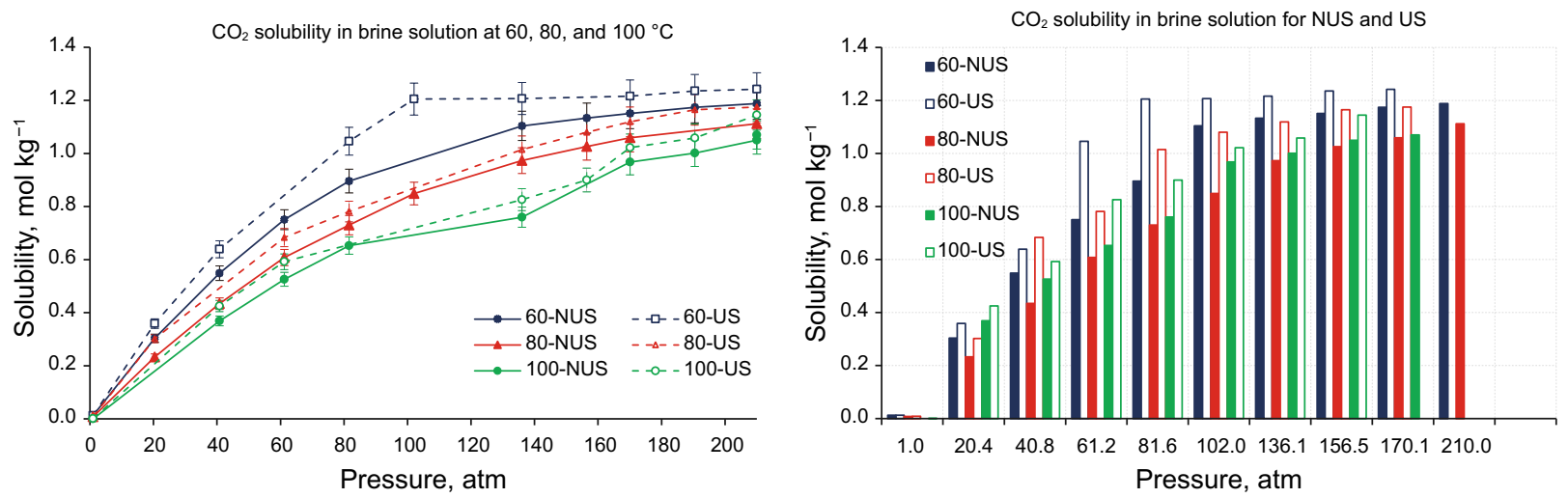

Fig. 4 The effect of ultrasound on solubility of $\mathrm{CO}_{2}$ in brine solution $(10,000 \mathrm{ppm})$ at 60,80 , and $100{ }^{\circ} \mathrm{C}$

that the solubility mechanism becomes less effective in aquifers with a high level of salinity.

The effects of ultrasound on the solubility of $\mathrm{CO}_{2}$ in distilled water at different temperature and pressure conditions are shown in Fig. 2. In addition, the effects of ultrasound (US) on the solubility of $\mathrm{CO}_{2}$ in brine solutions (1000 and 10,000 ppm $\mathrm{NaCl}$ ) are shown in Figs. 3 and 4, and the results were compared with the cases where no ultrasound (NUS) was used. It is apparent from the figures that in all the cases, the solubility of $\mathrm{CO}_{2}$ was improved by applying ultrasound. For instance, in the experiments using brine solution (1000 ppm), the solubility at $80 \mathrm{~atm}$ and $60{ }^{\circ} \mathrm{C}$ under ultrasound effects was $1.06 \mathrm{~mol} \mathrm{~kg}^{-1}$, whereas under the same pressure and temperature conditions, without applying ultrasound, the solubility was $0.924 \mathrm{~mol} \mathrm{~kg}^{-1}$. Thus, around $13 \%$ increase 
in the solubility of $\mathrm{CO}_{2}$ with the application of ultrasound was observed. The increase in the solubility of $\mathrm{CO}_{2}$ might be attributed to cavitation generated by ultrasound where cavitation could be defined as development, growth, and implosive collapse of bubbles in a liquid. Based on previous studies, the collapse of these bubbles could be considered as an adiabatic process, which leads to an enormous accumulation of energy inside the bubbles (Suslick 1989). This mechanism causes extremely high-temperature and pressure conditions in a microscopic region under the influence of sound waves. Therefore, we might conclude that as the solubility of $\mathrm{CO}_{2}$ in water is high, more nuclei would be available for cavitation to take place, and therefore, bubble growth become easier. And as the cavitation continues, the induced high pressure pushes $\mathrm{CO}_{2}$ molecules into the aqueous phase. Therefore, pressure surges that occur in the system as a result of cavitation could be the main reason behind higher solubility of $\mathrm{CO}_{2}$ in the presence of ultrasound.

A vast range of outcomes could result from the cavitation such as increased chemical activity in the solution due to the formation of primary and secondary radical reactions. Therefore, this might lead to an improvement of mass and heat transfer processes between the gas and liquid phases. However, the detailed analysis of these mechanisms during $\mathrm{CO}_{2}$ dissolution is not the focus of this study (Samenov et al. 2010; Santos et al. 2011; Laugier et al. 2008; Chen 2012).

It should also be noted that application of ultrasonic waves is associated with an increase in the temperature (Hamidi et al. 2013); therefore, one may argue that the increase in the temperature as a result of cavitation supposedly should result in a lower solubility of $\mathrm{CO}_{2}$ in brine (Mohammadian et al. 2015; Duan and Sun 2003). This might be explained as the dominance pressure increases due to cavitation over the temperature effects. The later discussion could be the subject of further micro-scale studies to clarify the mechanisms involved with the solubility of $\mathrm{CO}_{2}$ in brine in the presence of cavities.

In addition, higher external pressure reduces the vapour pressure of brine, which means higher intensity is needed to induce the cavitation by $\mathrm{CO}_{2}$ (Vajnhandl and Megharaj 2005). The higher pressure may enhance the cavitation and collapse of $\mathrm{CO}_{2}$ bubbles process; thus, it increases the dissolution of $\mathrm{CO}_{2}$ in brine. Also incremental temperature induced by the ultrasonic equipment results in an increase in sonochemical reaction rates. The increase in cavitation intensity is caused by lowering vapour pressure and thus reducing the amount of vapour diffused into the bubbles to cushion the cavitational collapse (Adewuyi 2001). There are other mechanisms that involve molecular dynamics and phase behaviour of $\mathrm{CO}_{2}$ and water which are beyond the scope of this study and need more investigation to understand the dissolution process.

\section{Conclusion}

Increasing pressure can enhance the dissolution of $\mathrm{CO}_{2}$ over a range of pressure; afterwards, a plateau for the solubility of $\mathrm{CO}_{2}$ can be observed. On the other hand, temperature and salinity inversely affect the dissolution of $\mathrm{CO}_{2}$. There are different mechanisms including molecular dynamics, vibration energy and phase behaviour responsible for such processes. Increasing pressure can reduce the vibration energy of $\mathrm{CO}_{2}$ molecules, and this can help in making bonds between $\mathrm{CO}_{2}$ and water molecules. On the other hand, higher temperature can increase the vibration energy of $\mathrm{CO}_{2}$ molecules, and higher salinity can decrease the chance of bonding of $\mathrm{CO}_{2}$ with water molecules as $\mathrm{Na}^{+}$and $\mathrm{Cl}^{-}$free ions occupy some of the places for intramolecular bonding with water molecules. As a result, both of these phenomena reduce the solubility of $\mathrm{CO}_{2}$.

In the ultrasound-assisted dissolution experiments, it was found that ultrasonic waves can improve the solubility of $\mathrm{CO}_{2}$ through complex mechanisms. These mechanisms might involve processes such as cavitation, bubble formation and sonochemical effects associated with ultrasonic waves among others. As a result, ultrasonic waves can improve the solubility of $\mathrm{CO}_{2}$ in brine. It was found that a specific range of ultrasonic wave frequencies could be applied to improve the solubility of $\mathrm{CO}_{2}$, beyond which the application of ultrasound can have a destructive impact on the dissolution process.

Open Access This article is distributed under the terms of the Creative Commons Attribution 4.0 International License (http://creative commons.org/licenses/by/4.0/), which permits unrestricted use, distribution, and reproduction in any medium, provided you give appropriate credit to the original author(s) and the source, provide a link to the Creative Commons license, and indicate if changes were made.

\section{References}

Abramov VO, Abramova AV, Bayazitov VM, et al. Sonochemical approaches to enhanced oil recovery. Ultrason Sonochem. 2015;25:76-81. doi:10.1016/j.ultsonch.2014.08.014.

Abramov VO, Mullakaev MS, Abramova AV, et al. Ultrasonic technology for enhanced oil recovery from failing oil wells and the equipment for its implementation. Ultrason Sonochem. 2013;20:1289-95. doi:10.1016/j.ultsonch.2013.03.004.

Abramov VO, Abramova AV, Bayazitov VM, et al. Selective ultrasonic treatment of perforation zones in horizontal oil wells for water cut reduction. Appl Acoust. 2016;103:214-20. doi:10. 1016/j.apacoust.2015.06.017.

Adewuyi YG. Sanochemistry: environmental science and engineering applications. Eng Chem Res. 2001;40:4681-715.

Azdarpour A, Asadullah M, Mohammadian E, et al. A review on carbon mineral carbonation through $\mathrm{pH}$-swing process. Chem Eng J. 2015;279:615-30. doi:10.1016/j.cej.2015.05.064.

Bachu S. Sequestration of $\mathrm{CO}_{2}$ in geological media: criteria and approach for site selection in response to climate change. Energy 
Convers Manag. 2000;41(9):953-70. doi:10.1016/S01968904(99)00149-1.

Bamberger A, Sieder G, Maurer G. High-pressure (vapor + liquid) equilibrium in binary mixtures of (carbon dioxide + water or acetic acid) at temperatures from 313 to $353 \mathrm{~K}$. J Supercrit Fluids. 2000;17:97-110. doi:10.1016/S0896-8446(99)00054-6.

Brooks CEP. Climatic fluctuations and the circulation of the atmosphere. Weather. 1950;5(3):113-9. doi:10.1002/j.14778696.1950.tb01161.x.

Bryant S. Geologic $\mathrm{CO}_{2}$ storage-Can the oil and gas industry help save the planet? J Pet Technol. 2007;59(9):98-105. doi:10.2118/ 103474-JPT.

Carroll JJ, Slupsky JD, Mather AE. The solubility of carbon dioxide in water at low pressure. J Phys Chem Ref Data. 1991;20:1201-9. doi:10.1063/1.555900.

Chen D. Applications of ultrasound in water and wastewater treatment. Handbook on application of ultrasonic: sonochemistry for sustainability. Boca Raton: CRC Press, Taylor and Francis Group; 2012

Duan $\mathrm{ZH}$, Sun R. An improved model calculating $\mathrm{CO}_{2}$ solubility in pure water and aqueous $\mathrm{NaCl}$ solutions from 273 to $533 \mathrm{~K}$ and from 0 to 2000 bar. Chem Geol. 2003;193:257-71. doi:10.1016/ S0009-2541(02)00263-2.

El-Maghraby RM, Pentland CH, Iglauer S, et al. A fast method to equilibrate carbon dioxide with brine at high pressure and elevated temperature including solubility measurements. J Supercrit Fluids. 2012;62:55-9. doi:10.1016/j.supflu.2011.11.002.

Gibson-Poole CM, Edwards S, Langford RP, et al. Review of geological storage opportunities for carbon capture and storage (CCS) in Victoria-summary report. Cooperative Research Centre for Greenhouse Gas Technologies, ICTPL-RPT07-0526, 2007.

Hamida T, Babadagli T. Investigations on capillary and viscous displacement under ultrasonic waves. J Can Pet Technol. 2006;45(2):16-9. doi:10.2118/06-02-TN2.

Hamida T, Babadagli T. Fluid-fluid interaction during miscible and immiscible displacement under ultrasonic waves. Eur Phys J B. 2007;60:447-62. doi:10.1140/epjb/e2008-00005-5.

Hamidi H, Rafati R, Junin RB, et al. A role of ultrasonic frequency and power on oil mobilization in underground petroleum reservoirs. J Pet Explor Prod Technol. 2012;2(1):29-36. doi:10.1007/s13202-012-0018-x.

Hamidi H, Rafati R, Junin R, et al. A technique for evaluating the oil/ heavy-oil viscosity changes under ultrasound in a simulated porous medium. Ultrasonics. 2013;54(2):655-62. doi:10.1016/j. ultras.2013.09.006.

Hamidi H, Mohammadian E, Asadullah M, et al. Effect of ultrasound radiation duration on emulsification and demulsification of paraffin oil and surfactant solution/brine using Hele-Shaw models. Ultrason Sonochem. 2015a;26:428-36. doi:10.1016/j. ultsonch.2015.01.009.

Hamidi H, Mohammadian E, Rafati R, et al. Effect of ultrasonic waves on the phase behavior of a surfactant-brine-oil system. Colloids Surf A. 2015b;482:27-33. doi:10.1016/j.colsurfa.2015. 04.009.

King MB, Mubarak A, Kim JD, et al. The mutual solubilities of water with supercritical and liquid carbon dioxides. J Supercrit Fluids. 1992;5(4):296-302. doi:10.1016/0896-8446(92)90021-B.

Koschel D, Coxam JY, Rodier L, et al. Enthalpy and solubility data of $\mathrm{CO}_{2}$ in water and $\mathrm{NaCl}$ (aq) at conditions of interest for geological sequestration. Fluid Phase Equilib. 2006;247:107-20. doi:10.1016/j.fluid.2006.06.006.

Paul EE, Naylor M, Stuart H, Curtis A. $\mathrm{CO}_{2}$ /brine surface dissolution and injection: $\mathrm{CO}_{2}$ storage enhancement," SPE offshore Europe paper presentation, Aberdeen, UK, 2010;6(1):41-53. doi:10. 2118/124711PA.
Laugier F, Andriantsiferana C, Wilhelm AM, et al. Ultrasound in gasliquid systems: effects on solubility and mass transfer. Ultrason Sonochem. 2008;15:965-72. doi:10.1016/j.ultsonch.2008.03.003.

Li ZW, Dong MZ, Li SL, et al. Densities and solubilities for binary systems of carbon dioxide plus water and carbon dioxide plus brine at $59{ }^{\circ} \mathrm{C}$ and pressures to $29 \mathrm{MPa}$. J Chem Eng Data. 2004;49(4):1026-31. doi:10.1021/je049945c.

Mao S, Zhang D, Li Y, et al. An improved model for calculating $\mathrm{CO}_{2}$ solubility in aqueous $\mathrm{NaCl}$ solutions and the application to $\mathrm{CO}_{2}-\mathrm{H}_{2} \mathrm{O}-\mathrm{NaCl}$ fluid inclusions. Chem Geol. 2013;347:4358. doi:10.1016/j.chemgeo.2013.03.010.

Mason TJ. Chemistry with ultrasound, critical report on applied chemistry, published for SCI by Elsevier Science Publishers, vol. 28, London, 1990.

Metz B, Davidson O, Coninck H, et al. Carbon dioxide capture and storage. IPCC Special Report prepared by Working Group III of the Intergovernmental Panel on Climate Change, Cambridge, UK, 2005.

Mohammadian E, Hamidi H, Assadullah M, et al. Measurement of $\mathrm{CO}_{2}$ solubility in $\mathrm{NaCl}$ brine solutions at different temperatures and pressures using the potentiometric titration method. J Chem Eng Data. 2015;60(7):2042-9. doi:10.1021/je501172d.

Naderi K, Babadagli T. Influence of intensity and frequency of ultrasonic waves on capillary interaction and oil recovery from different rock types. Ultrason Sonochem. 2010;17:500-8. doi:10. 1016/j.ultsonch.2009.10.022.

Nguyen DN. Carbon dioxide geological sequestration: technical and economic reviews. In: SPE/EPA/DOE Exploration and Production Environmental Conference, San Antonio, Texas, USA, 2003. doi:10.2118/81199MS.

Peper S, Dohrn R. Sampling from fluid mixtures under high pressure: review, case study and evaluation. J Supercrit Fluids. 2012;66:2-15. doi:10.1016/j.supflu.2011.09.021.

Portier S, Rochelle C. Modelling $\mathrm{CO}_{2}$ solubility in pure water and $\mathrm{NaCl}$-type waters from 0 to $300{ }^{\circ} \mathrm{C}$ and from 1 to 300 bar: application to the Utsira Formation at Sleipner. Chem Geol. 2005;217(3):187-99. doi:10.1016/j.chemgeo.2004.12.007.

Reichle D, Houghton J, Kane B, et al. Carbon sequestration research and development. US Department of Energy Report DOE/SC/ FE-1, Washington DC, USA, 1999.

Rumpf B, Nicolaisen H, Ocal C, et al. Solubility of carbon dioxide in aqueous solutions of sodium chloride: experimental results and correlation. J Solution Chem. 1994;23:431-48. doi:10.1007/ BF00973113.

Samenov IA, Ulyanov BA, Kulov NN. Effect of ultrasound on the dissolution of carbon dioxide in water. Theor Found Chem Eng. 2010;45(1):21-5. doi:10.1134/S0040579511010106.

Santos R, Ceulemans P, Francois D, et al. Ultrasound-enhanced mineral carbonation. In: The 3rd European Process Intensification Conference. ICheme Symposium Series no. 157. 2011.

Sengul M. $\mathrm{CO}_{2}$ sequestration: a safe transition technology. Paper SPE 98617 presented at SPE International Conference on Health, Safety, and Environment in Oil \& Gas Exploration and Production, Abu Dhabi, UAE, 2006. doi:10.2118/98617MS.

Schrag DP. Preparing to capture carbon. Science. 2007;315(5813): 812-3. doi:10.1126/science.1137632.

Shedid AS, Adel MS. Experimental investigations of $\mathrm{CO}_{2}$ solubility and variations in petrophysical properties due to $\mathrm{CO}_{2}$ storage in carbonate reservoir rocks. In: SPE North Africa Technical Conference and Exhibition, Cairo, Egypt, 2013. doi:10.2118/164632-MS.

Suslick KS. The chemical effects of ultrasound. USA: Scientific American; 1989. p. 62-8.

Tong DM, Vega-Maza D, Trusler M. Solubility of $\mathrm{CO}_{2}$ in aqueous solutions of $\mathrm{CaCl}_{2}$ or $\mathrm{MgCl}_{2}$ and in a synthetic formation brine at temperatures up to $423 \mathrm{~K}$ and pressures up to $40 \mathrm{MPa}$. J Chem 
Eng Data. 2013;58(7):2116-24. doi:10.1021/je400396s@ proofing.

Vajnhandl S, Megharaj AML. Ultrasound in textile dyeing and the decolourization/mineralization of textile dyes. Dyes Pigments. 2005;65:89-101. doi:10.1016/j.dyepig.2004.06.012.

Wiebe R, Gaddy VL. The solubility in water of carbon dioxide at 50, 75 and $100{ }^{\circ} \mathrm{C}$ at pressures to $700 \mathrm{~atm}$. J Am Chem Soc. 1939; 61:315-8. doi:10.1021/ja01871a025.

Yan W, Huang S, Stenby EH. Measurement and modelling of $\mathrm{CO}_{2}$ solubility in $\mathrm{NaCl}$ brine and $\mathrm{CO}_{2}$ - saturated $\mathrm{NaCl}$ brine density.
Int J Greenh Gas Control. 2011;5(6):1460-77. doi:10.1016/j. ijggc.2011.08.004.

Zheng DQ, Guo TM, Knapp H. Experimental and modeling studies on the solubility of $\mathrm{CO}_{2}, \mathrm{CHC}_{1} \mathrm{~F}_{2}, \mathrm{CHF}_{3}, \mathrm{C}_{2} \mathrm{H}_{2} \mathrm{~F}_{4}$ and $\mathrm{C}_{2} \mathrm{H}_{4} \mathrm{~F}_{2}$ in water and aqueous $\mathrm{NaCl}$ solutions under low pressures. Fluid Phase Equilib. 1997;129:197-209. doi:10.1016/S0378-3812(96) 03177-9.

Zumdahl SS. Chemical principles. 4th ed. Boston: Houghton Mifflin Company; 2002. 